\title{
Feminismo, Capitalismo e Ecologia ${ }^{* 1}$
}

\section{Feminism, Capitalism, and Ecology}

Dra. Johanna Oksala*2

joksala@luc.edu

Loyola University Chicago [EUA]
Tradução Dra. Juliana Lira Sampaio*3

jlirasampaio@gmail.com

Colégio Pedro II [RJ]

Revisão da Tradução

Clio Francesca Tricarico*4

Este artigo avalia criticamente os diferentes modos de conectar teoricamente feminismo, capitalismo e ecologia. Tomo a tradição existente do ecofeminismo socialista como ponto de partida e delineio dois diferentes modos pelos quais as conexões entre o capitalismo, a subordinação das mulheres e a destruição do meio ambiente têm sido produzidas nessa literatura: ecofeminismo materialista e ecofeminismo marxista. Demonstrarei as vantagens políticas e teóricas dessas posições em comparação com algumas das formas anteriores de teorização da relação entre mulheres e natureza, mas também as submeterei à crítica filosófica. Mostrarei como a posição ecofeminista marxista precisa ser atualizada e revisada, a fim de explicar os diferentes, e às vezes contraditórios, mecanismos para a capitalização da natureza que se tornaram proeminentes hoje. Destacarei dois desenvolvimentos em particular: o domínio do neoliberalismo e o desenvolvimento da biotecnologia. Concluirei resumindo as bases teóricas sobre as quais pode ser construída uma aliança política contemporânea entre lutas feministas e ecológicas contra o capitalismo.

PALAVRAS-ChAVE Feminismo. Capitalismo. Ecologia

\footnotetext{
*1 Nota das editoras: Tradução do artigo publicado originalmente no periódico Hypatia, X (X), p. 1-20, jan. 2018, DOI: 10.1111/hypa.12395. Agradecemos à professora Johanna Oksala o gentil e atencioso envio deste texto e, sobretudo, por ter providenciado generosamente os recursos que viabilizaram a autorização dos direitos de republicação do artigo neste dossiê. Artigo publicado originalmente como: Oksala, J. (2018), Feminism, Capitalism, and Ecology. Hypatia, 33: pp. 216-234. DOI:10.1111/hypa.12395.

*2 Professor Johanna Oksala é professora e pesquisadora no Departamento de Filosofia da Loyola University Chicago. Dedica-se à pesquisa nas áreas de filosofia política, filosofia feminista, filosofia ambiental e fenomenologia.

*3 Juliana Lira Sampaio é doutora em Filosofia pela UFRJ e Professora da Licenciatura em Filosofia e da Educação Básica, ambas no Colégio Pedro II, com ênfase de pesquisa em gêneros e sexualidades.
} 


\begin{tabular}{c|c|c} 
Feminismo, & Dra. Johanna & tradução: Dra. Juliana \\
Capitalismo e Ecologia & Oksala [LUC -EUA] & Lira Sampaio [CP II - R]]
\end{tabular}

This article critically assesses the different ways of theoretically connecting feminism, capitalism, and ecology. I take the existing tradition of socialist ecofeminism as my starting point and outline two different ways that the connections among capitalism, the subordination of women, and the destruction of the environment have been made in this literature: materialist ecofeminism and Marxist ecofeminism. I will demonstrate the political and theoretical advantages of these positions in comparison to some of the earlier forms of theorizing the relationship between women and nature, but I will also submit them to philosophical critique. I will show how the Marxist ecofeminist position needs to be both updated and revised in order to account for the different, sometimes contradictory mechanisms for the capitalization of nature that have become prominent today. I will underscore two developments in particular: the dominance of neoliberalism and the development of biotechnology. I will conclude by summing up the theoretical grounds on which a contemporary political alliance between feminist and ecological struggles against capitalism can be built.

KEYWORDS Feminism. Capitalism. Ecology. 


\begin{tabular}{c|c|c} 
Feminismo, & Dra. Johanna & tradução: Dra. Juliana \\
Capitalismo e Ecologia & Oksala [LUC -EUA] & Lira Sampaio [CP II - R]]
\end{tabular}

O termo ecofeminismo foi cunhado na década de 1970, quando o movimento ambiental emergente de grande escala se cruzou com os vários movimentos de justiça social, como o feminismo. O ecofeminismo continuou a se desenvolver como uma plataforma teórica e política ao longo dos anos 80 e produziu análises inovadoras sobre as opressões que se interseccionam entre a mulher e a natureza. ${ }^{1}$ No entanto, na década de 1990, começou a ser fortemente criticado pelo essencialismo, pelo etnocentrismo e pelo anti-intelectualismo. Em vez de se tornar um aspecto integrante da teoria feminista, complementando e corrigindo suas críticas antropocêntricas com perspectivas ecológicas, ecofeminista tornou-se quase um rótulo de escárnio. Como a ecofeminista americana Greta Gaard escreve provocativamente, ecofeministas passaram a ser vistas como "adoradores de deusas anti-intelectuais que erroneamente retratam a Terra como mulher e emitem mandatos totalizadores e a-históricos para o veganismo mundial" (GAARD, 2011, p. 32).

Uma reavaliação radical do ecofeminismo parece vital hoje, contudo, por razões políticas e teóricas. Primeiro, uma crítica feminista viável para o nosso tempo exige o enfrentamento direto da grave crise ecológica que estamos vivendo. Os problemas ambientais, particularmente as mudanças climáticas induzidas pelo homem, representam o maior desafio político que a humanidade enfrenta hoje e, portanto, nenhum movimento político pode permitir-se ignorar seu significado. Minha aposta é que, se o feminismo não se envolver seriamente com a ecologia e pensar sua relação com o ambientalismo, será difícil reconhecê-lo como uma força política relevante que molde nosso futuro de maneira significativa no século XXI.

Segundo, houve uma mudança teórica na academia: as questões ambientais não são mais consideradas apenas campo das ciências naturais. Pesquisadores das ciências humanas e sociais estão acordando para perceber que a maioria das questões ambientais hoje tem um profundo significado social, político e ético. As questões ambientais também têm importantes dimensões de gênero, além de consequências políticas concretas para a igualdade de gênero. Isso vale para questões variadas como justiça climática, segurança alimentar e justiça energética: elas exigem igualmente análises ecológicas e feministas. É importante, portanto, que a teoria feminista forme uma voz forte no desenvolvimento da discussão sobre questões ambientais nas humanidades e nas ciências sociais de hoje.

1 Para alguns textos fundamentais sobre ecofeminismo, cf. DALY, 1978, GRIFFIN, 1978, MERCHANT, 1980 e SHIVA, 1989. 


\begin{tabular}{c|c|c} 
Feminismo, & Dra. Johanna & tradução: Dra. Juliana \\
Capitalismo e Ecologia & Oksala [LUC -EUA] & Lira Sampaio [CP II - R]]
\end{tabular}

Terceiro, um caminho promissor para unir o feminismo e o ambientalismo hoje está surgindo através das críticas feministas contemporâneas ao capitalismo. Atualmente, as teóricas feministas estão se voltando cada vez mais à percepção de que o capitalismo deve constituir o quadro crítico para a compreensão das formas contemporâneas de subordinação das mulheres. Como escreve Nancy Fraser, depois de décadas nas quais o termo capitalismo raramente poderia ser encontrado fora dos escritos de pensadores marxistas, comentaristas de diferentes linhas de pesquisa agora se preocupam abertamente com a sustentabilidade do capitalismo, e ativistas de todo o mundo se mobilizam em oposição a suas práticas (cf. FRASER, 2014, p. 1). Em vez de entender isso como mera mudança na forma intelectual ou política, Fraser o vê como "um sintoma da crescente intuição de que os males sociais heterogêneos que nos cercam financeiros, econômicos, ecológicos, políticos, sociais - podem ser rastreados até os fundamentos estruturais comuns, e que reformas que não conseguem se envolver com estes estão fadados ao fracasso" (idem, p. 1). Minha opinião é que esse ressurgimento dos estudos feministas marxistas e socialistas abre caminhos interessantes para o reexame das conexões teóricas entre feminismo, capitalismo e ecologia.

O objetivo do meu artigo é estabelecer as bases filosóficas para tais projetos. $\mathrm{O}$ argumento prossegue em quatro etapas. Vou tomar a tradição existente do ecofeminismo socialista como ponto de partida e esboçar duas maneiras diferentes pelas quais as conexões entre o capitalismo, a subordinação das mulheres e a destruição do meio ambiente foram feitas nessa literatura. Eu distingo entre o ecofeminismo materialista fundamentado empiricamente e o ecofeminismo marxista que propõe um argumento estrutural sobre as conexões entre capitalismo, opressão de gênero e destruição ambiental. Essas duas posições teóricas são necessariamente simplificações de discussões muito mais complexas e variadas, e sua função aqui é meramente expor ao escrutínio crítico as diferentes bases filosóficas para defender o ecofeminismo anticapitalista. Na terceira seção, argumentarei que a posição do ecofeminismo marxista precisa ser igualmente atualizada e revisada, a fim de explicar os diferentes, e às vezes contraditórios, mecanismos que se destacam hoje para a capitalização da natureza. Ressaltarei dois desenvolvimentos em particular: o domínio do neoliberalismo e o desenvolvimento da biotecnologia. Concluirei resumindo as bases teóricas sobre as quais pode ser construída uma aliança política contemporânea entre lutas feministas e ecológicas contra o capitalismo. 


\begin{tabular}{c|c|c} 
Feminismo, & Dra. Johanna & tradução: Dra. Juliana \\
Capitalismo e Ecologia & Oksala [LUC -EUA] & Lira Sampaio [CP II - R]]
\end{tabular}

\section{Ecofeminismo materialista}

As críticas ao ecofeminismo visavam principalmente seu suposto essencialismo ontológico e metodológico. Com o domínio dos modos de pensar pós-estruturalistas nos anos 90, a unidade da categoria de mulheres já havia sido alvo de críticas intensas. $\mathrm{O}$ ecofeminismo não apenas parecia considerar a categoria de mulheres um dado, mas também afirmava a equiparação entre mulheres e natureza. Se a conexão entre mulheres e natureza era entendida como biológica ou social e historicamente construída, funcionava tradicionalmente como um instrumento fundamental da opressão das mulheres. $\mathrm{O}$ feminismo lutou duro contra a ideia de que as mulheres eram de alguma forma mais próximas da natureza do que os homens e, portanto, menos racionais, cultas e capazes de deliberação moral e política, por exemplo. O ecofeminismo parecia reverter esses argumentos enfatizando o elo inevitável entre mulheres e natureza, apenas reforçando, assim, as formas de dominação patriarcal.

Outro problema dizia respeito ao essencialismo metodológico inerente a grande parte da teorização ecofeminista da época. Esta parecia desconhecer os modos pelos quais suas próprias reivindicações e teorias foram socialmente construídas e incorporadas, muitas vezes em contextos sociais e políticos especificamente ocidentais. A acusação comum era a de que ela promoveu uma compreensão idealista e acrítica da suposta incorporação das mulheres de terceiro mundo na natureza e seu entendimento supostamente mais holístico. ${ }^{2}$ Assim, o ecofeminismo era, na melhor das hipóteses, uma distração irrelevante do trabalho real do feminismo de lidar com injustiças sociais, ou, na pior das hipóteses, uma forma de opressão em si.

Ecofeministas materialistas foram capazes de subverter essas armadilhas fazendo um argumento empírico, mais limitado. Elas evitaram as acusações do essencialismo ao rejeitar todas as conexões espirituais, abstratas e totalizadoras entre mulheres e natureza, e enfatizaram, em vez disso, as condições materiais reais das mulheres em contextos geográficos e culturais específicos. Com base em tal ênfase, foi possível argumentar que as mulheres em muitas partes do sul global, por exemplo, eram "mais próximas da natureza" apenas no sentido muito concreto e material de que elas, tipicamente, tinham de buscar água e lenha, além de serem responsáveis pela agricultura de subsistência em pequena escala, garantindo a sobrevivência de suas famílias. Isso significava que elas eram frequentemente as primeiras vítimas da destruição ambiental.

2 Sobre críticas feministas ao ecofeminismo visando seu etnocentrismo e sua tendência a essencializar a conexão mulher-natureza, cf. AGARWAL, 1992 e 2001, BRAIDOTTI [et al.], 1994 e NANDA, 1997. 


\begin{tabular}{c|c|c} 
Feminismo, & Dra. Johanna & tradução: Dra. Juliana \\
Capitalismo e Ecologia & Oksala [LUC -EUA] & Lira Sampaio [CP II - R]]
\end{tabular}

Em sua defesa do ecofeminismo materialista, Greta Gaard e Lori Gruen, por exemplo, reconhecem que a degradação ambiental afeta todas as pessoas e não é uma questão exclusivamente feminina. Seu argumento é que, mesmo assim, trata-se de uma questão feminista porque mulheres e crianças são as primeiras a sofrerem suas consequências. "Globalmente, as mulheres produzem aproximadamente $80 \%$ do suprimento de alimentos do mundo e, por esse motivo, são mais severamente afetadas pela escassez de alimentos e combustíveis e pela poluição dos recursos hídricos" (GAARD; GRUEN, 2005, 163). Segundo as autoras, não é, portanto, necessário evocar ideias metafóricas ou essencialistas sobre a maior propensão das mulheres à proteção da natureza, porque para as mulheres que vivem em condições materiais adversas, o ativismo ambiental é simplesmente uma forma de autodefesa (cf. também MELLOR, 1992, p. 7). Ideias semelhantes são apresentadas no estudo do Fundo das Nações Unidas para a População (United Nations Population Fund's - UNFPA) sobre as consequências das mudanças climáticas:

\footnotetext{
As mulheres - principalmente as dos países pobres - serão afetadas diferentemente dos homens. Elas estão entre os mais vulneráveis às mudanças climáticas, em parte porque, em muitos países, compõem a maior parte da força de trabalho agrícola e em parte porque tendem a ter acesso a menos oportunidades de geração de renda [...] Seca e chuvas irregulares obrigam as mulheres a trabalharem mais para garantir comida, água e energia para suas casas (UNFPA, 2009).
}

Em outras palavras, o ecofeminismo materialista pode ser entendido com base no reconhecimento de que grupos específicos de mulheres têm uma conexão distinta com o meio ambiente por meio de suas interações diárias com ele. Nesses casos específicos, pelo menos, há um claro incentivo estratégico para o feminismo e o ambientalismo unirem forças: proteger o meio ambiente também melhora diretamente a vida das mulheres pobres.

Embora tais argumentos contextual e empiricamente fundamentados possam ser politicamente e estrategicamente importantes, eles fornecem fundamentos teóricos insuficientes para o ecofeminismo. Em vez de expor uma conexão sistêmica ou estrutural entre a opressão de gênero e a destruição ambiental, eles apenas descrevem seu atual entrelaçamento. Os problemas ambientais tendem a exacerbar os problemas sociais já existentes porque os grupos mais fracos e mais vulneráveis têm menos recursos para mitigá-los. Quando explicações 


\begin{tabular}{c|c|c} 
Feminismo, & Dra. Johanna & tradução: Dra. Juliana \\
Capitalismo e Ecologia & Oksala [LUC -EUA] & Lira Sampaio [CP II - R]]
\end{tabular}

mais sistêmicas do vínculo são fornecidas, são muitas vezes formuladas em termos frustrantemente vagos e se baseiam na ideia de dominações congêneres (twin dominations) de mulheres e natureza. A associação histórica e conceitual entre mulheres e natureza é entendida como politicamente significativa, porque formou uma justificativa importante para a dominação patriarcal: a feminização da natureza e a naturalização das mulheres são dois aspectos de um único processo histórico que funcionou como um requisito ideológico para a subordinação subsequente da mulher e da natureza.

Gwyn Kirk, por exemplo, argumenta que "a serviço da acumulação de capital, o patriarcado capitalista dominado por brancos [...] cria 'alteridade"”; oprime igualmente mulheres e natureza, mas também "pessoas de cor e pobres no mundo inteiro [...]. Esse processo contínuo de objetificação é o mecanismo central subjacente aos sistemas de opressão baseados em classe, raça, gênero e nação" (KIRK, 1997, p. 349). Mary Mellor expõe que "industrialismo, capitalismo, colonialismo, racismo e patriarcado são as diferentes manifestações de uma Hidra de muitas cabeças que tem seus dedos em volta da garganta das mulheres, dos pobres e do planeta" (MELLOR, 1992, p. 155). Gaard e Gruen escrevem da mesma forma que "a atual crise ambiental global é o resultado das ideologias mutuamente reforçadas de racismo, sexismo, classismo, imperialismo, especismo e naturismo". Essas ideologias são melhor entendidas como "campos de força que se interseccionam entre si [...] para criar complexos sistemas de opressão interrelacionados e que se reforçam mutuamente" (GAARD; GRUEN, 2005, p. 170).

Listar ideologias opressivas e notar que elas se interseccionam ou se conectam entre si é obviamente válido no sentido de que elas devem ocorrer em algum tipo de totalidade social. Tais explicações abrangentes podem ajudar as feministas a descrever experiências ou instâncias nas quais diferentes eixos de dominação se interseccionam, mas não explicam como e por que ocorrem juntos em formas específicas. ${ }^{3}$ Se o feminismo ecológico parece cobrir todas as formas de opressão e injustiça, corre mais o risco de perder um claro foco teórico e objetivo político. O ecofeminismo materialista seria, na melhor das hipóteses, a uma instância de "política de afinidade", uma formação flexível capaz de acomodar muitas posições teóricas e políticas diferentes por trás dos

3 A crítica marxista-feminista da teoria da interseccionalidade se concentrou nessa questão em particular. Sarah Farris, por exemplo, argumenta que, embora a teoria da interseccionalidade fale claramente com os marxistas porque se recusa a tratar as opressões raciais e de gênero como formas secundárias de opressão, fica aquém de apresentar a teoria abrangente que promete (cf. FARRIS, 2015). Para textos seminais sobre a teoria da interseccionalidade, cf. CRENSHAW, 1989 e COLLINS, 1990. 


\begin{tabular}{c|c|c} 
Feminismo, & Dra. Johanna & tradução: Dra. Juliana \\
Capitalismo e Ecologia & Oksala [LUC -EUA] & Lira Sampaio [CP II - R]]
\end{tabular}

objetivos gêmeos de "sobrevivência planetária e um futuro igualitário" (CARLASSARE, 2000, p. 101).

Afirmo que a principal contribuição das pensadoras feministas marxistas para o projeto do ecofeminismo tem sido a percepção de que podemos identificar mecanismos distintos específicos da lógica sistêmica do capitalismo que unem opressão de gênero e destruição ambiental. Em outras palavras, o ecofeminismo marxista não apenas repudia o essencialismo de gênero, insistindo que a conexão entre opressão de gênero e devastação ambiental é histórica e culturalmente específica, mas por meio de sua análise crítica do capitalismo, é capaz de fornecer um argumento rigoroso sobre por que essa conexão é, no entanto, estrutural e não apenas historicamente contingente ou acidental. A feminização da natureza e a naturalização das mulheres não funcionam meramente como justificativas ideológicas para uma lógica abstrata e geral de dominação, mas estruturam concretamente a sociedade capitalista por meio de práticas sociais e econômicas de gênero e divisões do trabalho. $\mathrm{O}$ caráter sistêmico da conexão entre opressão de gênero e devastação ambiental se torna discernível quando reconhecemos a função indispensável que a naturalização do trabalho reprodutivo das mulheres desempenha no capitalismo contemporâneo.

\section{Ecofeminismo marxista}

A maioria dos teóricos marxistas-feministas que escreveram nas décadas de 1970 e 1980 sobre o trabalho reprodutivo e cuidador das mulheres teorizou-o como uma forma de trabalho e se apropriou do quadro marxista com a intenção de expor os mecanismos de exploração. Os debates sobre o trabalho doméstico, por exemplo, eram essencialmente relacionados à questão de saber se o trabalho doméstico ou reprodutivo das mulheres era um trabalho produtivo e produzia mais-valia (cf. BENSTON 1997, FEDERICI, 2012 e VOGEL, 2013). Uma vertente distinta desse estudo, no entanto, concentrou-se na ideia de acumulação primitiva. A ideia de acumulação primitiva se prestou mais prontamente à teorização ecofeminista, porque não estava preocupada com a produtividade do trabalho humano, mas focada nas suas pré-condições necessárias. Conseguiu trazer para as análises marxistas-feministas atividades e recursos que eram produtivos para valores de uso (use-values) importantes, mas não para valor de troca, e, portanto, foram estruturalmente excluídos dos mercados de commodities.

A acumulação primitiva se refere à percepção de que a acumulação capi- 


\begin{tabular}{c|c|c} 
Feminismo, & Dra. Johanna & tradução: Dra. Juliana \\
Capitalismo e Ecologia & Oksala [LUC-EUA] & Lira Sampaio [CP II - R]]
\end{tabular}

talista nunca conseguiu operar apenas com os mecanismos de exploração da força de trabalho e a apropriação da mais-valia. Sempre contou fortemente com pilhagem e roubo. Como Marx formulou a famosa ideia no primeiro volume do Capital, o capital vem ao mundo "pingando da cabeça aos pés, de todos os poros, com sangue e sujeira” (MARX, 1976, p. 435). A acumulação primitiva é um processo de expropriação inerentemente violento, extraindo recursos e apropriando-se deles gratuitamente ou sem compensação adequada. Exemplos incluem o cerco dos bens comuns, a migração forçada e o comércio de escravos. A dominação da natureza e a extração de recursos naturais podem ser vistas como outro exemplo de acumulação primitiva: os valores de uso produzidos naturalmente são saqueados para o consumo produtivo como matéria-prima e tratados como mercadorias nos circuitos capitalistas da valorização. O colonialismo funcionou historicamente como uma estratégia política eficaz para esse tipo de expropriação: recursos como ouro, marfim e borracha foram extraídos do sul global para enriquecer o norte global.

Há um debate em andamento quanto a saber se a acumulação primitiva foi um processo histórico que precedeu o estabelecimento de formas de produção propriamente capitalistas ou se é melhor entendido como um processo contínuo. Marx o descreve como um processo histórico de transferência de riqueza da periferia do capitalismo para o centro que permitiu o surgimento de economias capitalistas na Europa, mas muitos pensadores marxistas contemporâneos enfatizam seu caráter contínuo e seus vínculos estruturais necessários com o capitalismo. ${ }^{4} \mathrm{~A}$ ideia de acumulação primitiva contínua é central para teóricos marxista-feministas como Maria Mies, que argumenta em seu trabalho seminal que tanto a natureza quanto o trabalho reprodutivo das mulheres são expropriados como um recurso livre no capitalismo (cf. MIES, 1986/1998). Mies cria um vínculo histórico e estrutural entre o nascimento do capitalismo, a colonização, a subordinação da natureza pela industrialização e a destruição simultânea da autonomia das mulheres sobre seus corpos, que caracterizou a caça às bruxas na Europa. Colônias, natureza e mulheres foram, assim, dominadas, controladas e violentamente expropriadas pelos homens capitalistas brancos de uma maneira estruturalmente semelhante e como parte do mesmo processo histórico impulsionado pelo objetivo da acumulação capitalista. ${ }^{5}$

4 David Harvey, por exemplo, renomeia a acumulação primitiva denominando-a acumulação por desapropriação (cf. HARVEY, 2003).

5 O trabalho de Ariel Salleh também foi central para estabelecer as fundações do ecofeminismo marxista. Em Ecofeminism as Politics, ela defende os objetivos políticos comuns das lutas feministas, socialistas, ecológicas e indígenas contra o capital transnacional (cf. SALLEH, 1997). 


\begin{tabular}{c|c|c} 
& & \\
Feminismo, & Dra. Johanna & tradução: Dra. Juliana \\
Capitalismo e Ecologia & Oksala [LUC -EUA] & Lira Sampaio [CP II - R]]
\end{tabular}

A violenta subordinação das mulheres aos homens e o processo de acumulação de capital foram encenados, pela primeira vez, em grande escala durante a caça às bruxas na Europa. Mas, desde então, constituiu a infraestrutura sobre a qual as chamadas relações capitalistas de produção poderiam ser estabelecidas, ou seja, a relação contratual entre os proprietários da força de trabalho e os proprietários dos meios de produção. Sem essa infraestrutura de trabalho feminino não livre, coercitivo ou colonial no sentido mais amplo, as relações de trabalho não coercitivas e contratuais dos proletários livres não seriam possíveis. As mulheres e os povos coloniais eram definidos como propriedade, como natureza, não como sujeitos livres que poderiam assinar um contrato. Ambos tinham de ser subordinados à força e pela violência direta. (MIES, 1986/1998, p. 170)

Mies usa a metáfora de um iceberg para ilustrar o modo pelo qual a exploração capitalista do trabalho assalariado se baseia em processos violentos de expropriação: o capitalismo é uma economia de iceberg em que capital e trabalho assalariado formam a economia visível contada no PIB e na qual o trabalho reprodutivo das mulheres, o trabalho nas colônias e a produção da natureza são externalizados da economia oficial e formam a grande parte subaquática (cf. idem, p. xi). Ideologicamente, os processos essenciais de externalização foram justificados pela naturalização das mulheres e das colônias: elas eram definidas como natureza descontrolada, perigosa e selvagem a ser subjugada pela força (cf. idem, p. 90). "No decorrer dos últimos quatro ou cinco séculos, mulheres, natureza e colônias foram externalizadas, declaradas fora da sociedade civilizada, empurradas para baixo e, assim, tornando-se, desse modo, invisíveis da mesma forma como a parte subaquática de um iceberg é invisível; ainda assim constituem a base do todo" (idem, p. 77). A lógica desse processo de externalização era simples: permitia aos capitalistas renunciarem aos custos que, de outra forma, teriam que cobrir. Quando o trabalho de mulheres e súditos coloniais era considerado um recurso natural, estava disponível gratuitamente como ar e água (cf. idem, p. 110).

Ainda segundo Mies, o mesmo processo de expropriação que caracterizou o capitalismo inicial ainda está em andamento, porque é um aspecto estrutural e necessário do capitalismo. A prevalência de violência direta e estrutural contra as mulheres, particularmente no sul global, deve ser entendida contra a lógica 


\begin{tabular}{c|c|c} 
Feminismo, & Dra. Johanna & tradução: Dra. Juliana \\
Capitalismo e Ecologia & Oksala [LUC-EUA] & Lira Sampaio [CP II - R]]
\end{tabular}

da acumulação primitiva contínua, que constitui a precondição para a exploração capitalista. Os exemplos de Mies variam de casos claros como escravidão e tráfico sexual a fenômenos mais complexos, como noivas por correspondência

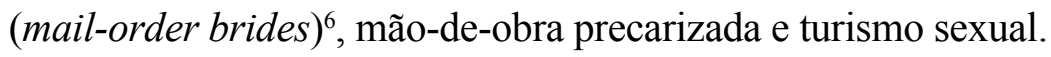

Nancy Fraser propôs um argumento semelhante recentemente. Ela também enfatiza os processos necessários e complementares da expropriação capitalista que não operam através da relação contratual, pela qual o capital compra força de trabalho em troca de salários. Em vez disso, a expropriação funciona confiscando capacidades e recursos e recrutando-os nos circuitos de valor do capital.

O confisco pode ser flagrante e violento, como na escravidão no Novo Mundo, ou pode ser velado por um disfarce de comércio, como nos empréstimos predatórios e execuções de dívidas da era atual [...] Os ativos confiscados podem ser trabalho, terra, animais, ferramentas, depósitos minerais ou energéticos, mas também seres humanos, suas capacidades sexuais e reprodutivas, suas filhos e órgãos corporais (FRASER, 2016, p. 166).

Portanto, embora alguns indivíduos tenham acesso ao mercado de trabalho possuam o direito de vender o seu trabalho e tenham a capacidade de competir no mercado - outros são simplesmente desapropriados de seus corpos, de suas terras e até de suas vidas, e tratados como descartáveis. Interseccionando com o gênero, a racialização tem funcionado e continua a funcionar como o instrumento chave para delinear o limite entre esses dois grupos. ${ }^{7}$

Para resumir esta seção, o argumento marxista-feminista sustenta que, além da apropriação da mais-valia produzida pelo trabalho assalariado, o capitalismo conta com a expropriação contínua e violenta de mulheres, povos indígenas, animais não humanos e a biosfera. A expropriação do trabalho reprodutivo das mulheres é, portanto, estruturalmente análoga e historicamente contemporânea à extração de recursos naturais. Em vários pontos da história e em diferentes

6 A expressão mail-order brides se refere a uma prática de arranjo matrimonial que consiste no auto-oferecimento à distância e por catálogo, de mulheres pertencentes aos países considerados em desenvolvimento para o casamento com homens de países ditos desenvolvidos com a finalidade de migração. (N. T.)

7 Michael Dawson argumenta que entender os fundamentos do capitalismo requer entender a distinção ontológica entre humanos superiores e inferiores - codificada como raça - que era necessária para a escravidão, o colonialismo, o roubo de terras nas Américas e o genocídio (cf. DAWSON, 2016, p. 147). 


\begin{tabular}{c|c|c} 
Feminismo, & Dra. Johanna & tradução: Dra. Juliana \\
Capitalismo e Ecologia & Oksala [LUC -EUA] & Lira Sampaio [CP II - R]]
\end{tabular}

graus hoje, as mulheres têm sido violentamente forçadas a abrir mão da autonomia sobre seus corpos e capacidades reprodutivas, e essas capacidades e o trabalho a elas relacionado foram extraídos delas gratuitamente e postos a serviço de acumulação de capital. Esse processo é mascarado e legitimado por um processo essencialmente ideológico que naturaliza as mulheres - entende-as como menos civilizadas, menos racionais e mais próximas da natureza.

Os fundamentos teóricos ou sistêmicos para vincular a opressão das mulheres à devastação ecológica não são principalmente ideológicos, mas funcionais. Tanto as mulheres como a natureza têm uma função similar e indispensável no mecanismo de expropriação: ocupam posições análogas na lógica da acumulação capitalista, na qual os mecanismos de exploração dependem da base invisível da expropriação. Em outras palavras, as mulheres e as colônias não são apenas concebidas como natureza, são expropriadas como natureza.

\section{A capitalização de naturezas}

Pensadores marxista-feministas como Mies fornecem um relato poderoso da extensão da expropriação capitalista, forjando um vínculo sistêmico entre capitalismo, opressão de gênero e devastação ecológica. Tal relato torna possível reunir caça às bruxas, colonialismo, minas a céu aberto e turismo sexual sob a mesma lógica sistêmica, mas a desvantagem é que acabamos com uma teorização muito abstrata sobre um conjunto de fenômenos extremamente amplo e heterogêneo - geográfica, cultural, histórica e teoricamente. Afirmo que essa estrutura requer, portanto, alguma revisão e atualização para torná-la mais precisa.

Além de identificar e analisar o impulso do capitalismo para expropriação, corte de custos e parasitismo (free-ride), discutido até agora, na minha opinião, é necessário também identificar pelo menos duas outras tendências inerentes que caracterizam as maneiras pelas quais o capitalismo hoje absorve tanto a natureza quanto o trabalho reprodutivo das mulheres em seus circuitos de valor: a comoditização da natureza como natureza e a real subsunção da natureza. Às vezes, esses mecanismos se fortalecem e se reforçam, mas outras vezes trabalham com propósitos contrários.

A identificação desses mecanismos adicionais deve ser vista como uma resposta às mudanças que ocorreram no capitalismo nas últimas décadas. Como muitos teóricos argumentam, o capitalismo hoje é mais fluido e flexível do que o capitalismo eurocêntrico que levou ao colonialismo dos séculos XVIII e XIX 


\begin{tabular}{c|c|c} 
Feminismo, & Dra. Johanna & tradução: Dra. Juliana \\
Capitalismo e Ecologia & Oksala [LUC -EUA] & Lira Sampaio [CP II - R]]
\end{tabular}

(cf. NANDA, 1997, p. 366). Quero destacar dois desenvolvimentos em particular: a ascensão do neoliberalismo como paradigma econômico dominante e o desenvolvimento espetacular da biotecnologia e sua extensiva comercialização.

\section{A comoditização da natureza como natureza}

De acordo com pensadores ecomarxistas como Mies, o principal problema com a expropriação da natureza do capitalismo (incluindo as capacidades reprodutivas das mulheres) é o parasitismo ("free-ride"): seu fracasso em pagar suas contas. A natureza é externalizada como um recurso gratuito, implicitamente assumido como infinito e, portanto, pode ser expropriado sem compensação. Como escreve Jason Moore, as "dádivas" da natureza não consistem em "frutos mais acessíveis" ("low-hanging fruit") que podem ser simplesmente colhidos. A ideia de acumulação primitiva efetivamente transmite como as "naturezas baratas" são de fato produzidas: elas são expropriadas por meio de processos violentos e destrutivos, como a escravidão ou as minas a céu aberto (cf. MOORE, 2015, p. 64).

No entanto, uma inclinação particularmente significativa que caracteriza o capitalismo neoliberal contemporâneo é a tendência oposta: a tentativa de internalizar cada vez mais atividades e ativos nos mercados capitalistas. Segundo a teoria econômica neoliberal, a comercialização é um meio particularmente eficaz de acelerar o crescimento econômico, uma vez que o PIB é medido em termos de transações de mercado. Portanto, mesmo que ainda possamos certamente identificar processos significativos de externalização em operação hoje - a poluição da atmosfera com gases de efeito estufa excessivos, por exemplo - também precisamos identificar mecanismos que busquem internalizar o ambiente de forma mais exaustiva nos mercados capitalistas. Enquanto nas fases iniciais do capitalismo ainda existiam territórios virgens para os investidores de risco descobrirem e desapropriarem, tais zonas externas são difíceis de encontrar hoje. O capitalismo de risco foi forçado a assumir novas formas imaginativas.

Neil Smith apresentou o poderoso argumento de que estamos vivendo atualmente um período em que nosso relacionamento socioeconômico com a natureza tem sido dramaticamente transformado: a natureza tornou-se capitalizada em uma extensão sem precedentes. A natureza capitalista sempre foi mercantilizada no sentido de que os valores de uso (use-values) naturalmente fornecidos foram saqueados para o consumo produtivo. Hoje, no entanto, toda uma nova 


\begin{tabular}{c|c|c} 
Feminismo, & Dra. Johanna & tradução: Dra. Juliana \\
Capitalismo e Ecologia & Oksala [LUC -EUA] & Lira Sampaio [CP II - R]]
\end{tabular}

gama de mercadorias ecológicas foi produzida. Smith escreve: "Enquanto a comoditização tradicional da natureza geralmente envolvia a colheita de valores de uso como matéria-prima para a produção capitalista - madeira para mesas, óleo para energia, minério de ferro para aço, vários grãos para pão -, essa nova geração de mercadorias é diferente" (SMITH, 2007, p. 17). As novas commoditiesecológicas, como créditos de carbono ou poluição, paradoxalmente comoditizam a natureza como natureza, enquanto algo que é produzido de modo externo à expropriação capitalista, mas depois é internalizado na economia capitalista, dando-lhes valor de troca. $\mathrm{O}$ valor da mercadoria produzida - por exemplo, uma área de floresta tropical que compensa certa quantidade de carbono produzido pelas viagens aéreas - repousa precisamente no fato de que não pode ser consumida produtivamente.

\footnotetext{
Proprietários de terras que possuem áreas de floresta (geralmente em países tropicais mais pobres) são pagos para não cortar suas florestas, enquanto os maiores poluidores em partes mais industriais do mundo podem comprar esses créditos como um meio de permitir que continuem a poluir (idem, p. 19).
}

Portanto, podemos identificar um movimento duplo: o capital externaliza custos - por exemplo, emitindo poluição - oferecendo oportunidades para acumulação de capital por meio de mecanismos de internalização por outras empresas (ou às vezes até as mesmas empresas) na forma de comércio de poluição, por exemplo. A apropriação do meio ambiente pelo capitalismo, portanto, usa igualmente mecanismos de internalização e externalização de forma relativamente flexível e dependendo do contexto social e político a fim de maximizar os lucros e alimentar o crescimento econômico. Nenhum conjunto de mecanismos está livre de problemas do ponto de vista ecológico. O parasitismo (free-riding) do capitalismo na natureza é obviamente problemático, mas a tentativa de proteger o meio ambiente, transformando-o em uma parte interna dos mercados capitalistas, também tem sérios problemas.

Primeiro, da perspectiva da economia, é difícil internalizar completamente as externalidades produzidas pelo meio ambiente no sistema de mercado autorregulado. O meio ambiente não é produzido como outras mercadorias; em vez disso, é uma totalidade complexa e integrada, que inclui toda a biosfera. Como explica John Bellamy Foster, para internalizar o ambiente dentro do sistema de mercado, ecossistemas complexos devem ser primeiramente divididos em bens 


\begin{tabular}{c|c|c} 
Feminismo, & Dra. Johanna & tradução: Dra. Juliana \\
Capitalismo e Ecologia & Oksala [LUC -EUA] & Lira Sampaio [CP II - R]]
\end{tabular}

e serviços distintos, como a qualidade do ar, uma espécie particular de planta ou animal, ou a manutenção da temperatura global, por exemplo. Essas partes específicas são, então, imputadas aos preços por meio da construção de curvas de oferta e demanda. O processo de precificação, entretanto, também é cheio de dificuldades. Na precificação hedônica, as preferências do consumidor são estabelecidas por meio da demanda por bens e serviços que estão intimamente associados a um determinado produto ambiental. No método de avaliação contingente, são construídos mercados hipotéticos e os consumidores são solicitados a indicar suas preferências por meio de pesquisas. Usando as respostas dessas pesquisas, os economistas, então, reúnem os resultados sobre toda a população, a fim de construir curvas de demanda para os hipotéticos commodities ambientais. Por fim, mecanismos de mercado e instrumentos de política são criados para alterar os preços nos mercados existentes ou criar novos mercados. Em razão das dificuldades em todas essas etapas, os mercados de proteção ambiental não funcionaram muito bem como mercados, mesmo em seus próprios termos (cf. FOSTER, 2002, p. 27-28). ${ }^{8}$

De uma perspectiva filosófica, os problemas com os mecanismos de internalização são talvez ainda mais graves. Como argumenta o filósofo Michael Sandel, por exemplo, os mercados fazem mais do que alocar bens e serviços; eles também expressam e promovem consideravelmente significados, valores e atitudes em relação aos bens e serviços trocados. Por meio de mecanismos de internalização, o ambiente se torna um conjunto de utilidades distintas, baseadas no mercado, cujo valor é determinado pelas preferências egoístas dos consumidores humanos. Portanto, o problema filosófico não se dirige apenas ao fato de ser tecnicamente difícil estabelecer preços corretos por meio de métodos de pesquisa, por exemplo, para consequentemente proteger aspectos do meio ambiente aos quais não foram atribuídos valores econômicos adequados. O problema consiste fundamentalmente no fato de que tais métodos não podem computar valores intrínsecos (cf. SANDEL, 2012).

Darei um exemplo do meu país natal, a Finlândia. O atual governo pretende cumprir as metas de energia e clima da UE com investimentos significativos em bioenergia. Os críticos dessa estratégia apontaram que, como se baseia em vasta exploração madeireira, de fato, acabará piorando as mudanças climáticas, diminuindo a capacidade das florestas existentes de agir como sumidouros de carbono. No debate que se seguiu, um argumento recorrente a favor da estratégia do governo tem sido afirmar que é possível aumentar a extração de

8 Para os graves problemas dos mercados europeus de carbono, cf. KLEIN, 2014, p. 224-25. 


\begin{tabular}{c|c|c} 
Feminismo, & Dra. Johanna & tradução: Dra. Juliana \\
Capitalismo e Ecologia & Oksala [LUC -EUA] & Lira Sampaio [CP II - R]]
\end{tabular}

madeira sem diminuir os sumidouros de carbono, cortando florestas antigas e depois substituindo-as por florestas mais jovens e de crescimento mais rápido, gerenciadas por intensivos sistemas de cultivo e que funcionem de modo mais eficaz como sumidouros de carbono. Independentemente de essa afirmação ser verdadeira ou não, o que o exemplo deve esclarecer é que, em tal estrutura, o fato de que as florestas são antigas e ecologicamente diversas não tem valor. Sua destruição não é causada por sua exclusão dos mecanismos de mercado destinados a proteger o meio ambiente, mas por sua inclusão neles. ${ }^{9}$

Quando reconhecemos que o ambiente e o trabalho reprodutivo das mulheres têm uma posição análoga na lógica da acumulação capitalista, podemos identificar uma mudança paralela na relação do capitalismo neoliberal com o trabalho reprodutivo das mulheres. Corresponde às recentes tentativas de mercantilizar o domínio privado e transformar as mulheres em assalariadas. A rápida neoliberalização de nossas economias nas últimas décadas resultou em mudanças significativas no papel tradicional das mulheres como prestadoras de cuidados em casa. Vimos a crescente transformação das atividades afetivas e de cuidado que as mulheres costumavam realizar em casa em serviços pagos, seja em creche, ajuda doméstica ou serviços de saúde. Em outras palavras, hoje o trabalho reprodutivo das mulheres não é tão externalizado dos mercados de commodities para o domínio privado e, em seguida, expropriado de graça; é cada vez mais internalizado nos mercados capitalistas e explorado como trabalho produtivo. Isso resultou em novas formas de opressão de gênero, pois muitas vezes são mulheres imigrantes, pobres, de minorias étnicas que agora acabam prestando serviços de assistência comoditizados. As chamadas $\mathrm{ca}$ deias globais de assistência ("global care chains") e o crescimento do tráfico de mulheres tornaram-se alguns dos efeitos de gênero desse desenvolvimento (cf. HOCHSCHILD, 2000).

O surgimento dessa economia de serviços feminizada também é inerentemente ligado à atual crise de assistência: a falta de um número suficiente de cuidadores qualificados que realmente se importam. Como as economistas feministas, em particular, apontaram, semelhante ao caso do meio ambiente, o trabalho de assistência cria importantes externalidades positivas que não podem ser totalmente captadas nas transações de mercado. Portanto, expõe alguns dos limites da comoditização do trabalho assistencial do ponto de vista econômico. Como explicam economistas como Nancy Folbre e Julie A. Nelson, muitas

9 Cf. AHO, 2016. Sobre pontos de vista que contestam a afirmação de que as florestas jovens são sumidouros de carbono mais eficazes, cf. Ilmasto.org, 2008. 


\begin{tabular}{c|c|c} 
Feminismo, & Dra. Johanna & tradução: Dra. Juliana \\
Capitalismo e Ecologia & Oksala [LUC -EUA] & Lira Sampaio [CP II - R]]
\end{tabular}

pessoas compartilham o benefício quando as crianças são educadas para serem adultos responsáveis, habilidosos e amorosos. Os empregadores se beneficiam de trabalhadores qualificados e cooperativos, os idosos se beneficiam se uma geração mais jovem e qualificada de trabalhadores gera altos impostos e assim por diante (cf. FOLBRE; NELSON, 2000). O problema é que esses ganhos não podem ser totalmente captados por quem os criou. Os pais, por exemplo, não podem exigir uma taxa dos empregadores que contratam seus filhos adultos. Isso significa que, à semelhança de outras externalidades, aquelas criadas pela assistência produzem um incentivo para o parasitismo (free-ride), permitindo que outras pessoas paguem os custos. Folbre e Nelson concluem que o mercado por si só não pode resolver a atual crise de assistência:

\footnotetext{
Na ausência de coordenação coletiva, será prestado um número menor do que a quantidade ideal de assistência, porque os prestadores de cuidados não são totalmente compensados pelo valor social de seus serviços. [...] Existem limites para a substituibilidade entre a oferta familiar e a de mercado, limites que nossa sociedade precisa discutir, definir e aplicar (FOLBRE; NELSON, 2000, p. 137).
}

Em suma, podemos identificar duas maneiras opostas de conectar a lógica econômica capitalista à divisão de trabalho de gênero - o capitalismo quer que as mulheres trabalhem e fiquem em casa - e podemos encontrar exemplos de ambos os incentivos hoje. O capitalismo externaliza os custos do trabalho reprodutivo, esperando que as mulheres cuidem de suas casas de graça, além de internalizá-las criando novos mercados para o trabalho de assistência. Mais uma vez, semelhante ao ambiente, nenhuma das opções é livre de problemas. Quando o trabalho reprodutivo não é comoditizado, temos o problema do parasitismo; quando se transforma em serviços pagos, enfrentamos a crise da assistência. ${ }^{10}$ Como argumentarei na conclusão, isso sugere que apenas atacar o neoliberalismo em favor de formas mais social-democráticas de capitalismo não resolverá os problemas de opressão de gênero ou de devastação ambiental no capitalismo. As transformações políticas e econômicas necessárias precisam ser mais radicais e contestar a lógica central do próprio capitalismo.

10 Para mulheres individuais, isso significa que elas estão cada vez mais divididas entre as demandas conflitantes da feminilidade nas sociedades capitalistas neoliberais (cf. OKSALA, 2011). 


\begin{tabular}{c|c|c} 
Feminismo, & Dra. Johanna & tradução: Dra. Juliana \\
Capitalismo e Ecologia & Oksala [LUC-EUA] & Lira Sampaio [CP II - R]]
\end{tabular}

\section{A subsunção real da natureza}

Além dos mecanismos de internalização proeminentes no capitalismo neoliberal, defendo que os mecanismos de expropriação - o parasitismo (free-ride) sobre a natureza - devem ser complementados com outro conjunto distinto de mecanismos para a capitalização da natureza. Esses mecanismos visam manipular e intensificar a produtividade biológica, tornando os ativos naturais (com base biológica) mais rentáveis ou maleáveis para exploração comercial. Tais mecanismos são teorizados de forma esclarecedora como a subsunção real da natureza em um influente artigo de William Boyd, Scott Prudham e Rachel Schurman (2001). Inspirados pelas noções de Marx sobre subsunção formal e real do trabalho, Boyd e seus colegas formulam os conceitos da subsunção formal e subsunção real da natureza, a fim de distinguir duas maneiras diferentes pelas quais o capitalismo se apropria da natureza. ${ }^{11}$

A subsunção formal da natureza corresponde aproximadamente aos mecanismos de expropriação ou acumulação primitiva discutidos acima em conexão com o trabalho de Mies. Sob a subsunção formal da natureza, as empresas capitalistas tentam obter acesso ou controlar os recursos naturais, mas são "incapazes de controlar, intensificar, manipular ou de outra forma melhorar a natureza para se adequar a seus objetivos" (BOYD; PRUDHAM; SCHURMAN, 2001, p. 562). O capital opera com uma lógica de extração e confronta o mundo natural como um determinado conjunto de processos biofísicos e características materiais. Apesar de seus benefícios óbvios, essa abordagem geralmente implica obstáculos à acumulação, porque as empresas precisam ajustar as suas estratégias de produção para atender às exigências da natureza. A dependência de cronogramas de produção natural, por exemplo, pode colocar sérios desafios para a implantação contínua de mão-de-obra e máquinas. É por isso que o desenvolvimento de mecanismos para a subsunção real da natureza se torna essencial.

A subsunção real da natureza refere-se a estratégias pelas quais o capital busca alterar intencionalmente processos biofísicos a fim de superar obstáculos na produção, obter vantagem competitiva e aumentar a lucratividade. A lógica da extração é substituída por uma lógica que busca aumentar a produtividade biológica. "O resultado desejado [...] consiste em rendimentos mais altos, tempos

11 No que diz respeito à real subsunção do trabalho, Marx se referiu à maneira pela qual o capital não apenas assume e administra um processo de trabalho já existente, mas transforma completamente a sua natureza e, por extensão, os próprios trabalhadores. Essa ideia foi essencial para expor a transição histórica a uma forma de capitalismo na qual a mais-valia é extraída principalmente com base no aumento da produtividade do trabalho, e não por meio de uma extensão da jornada de trabalho (cf. MARX, 1976, p. 645 e p. 1019-38). 


\begin{tabular}{c|c|c} 
Feminismo, & Dra. Johanna & tradução: Dra. Juliana \\
Capitalismo e Ecologia & Oksala [LUC-EUA] & Lira Sampaio [CP II - R]]
\end{tabular}

de rotatividade mais curtos, resistência melhorada a doenças etc. A natureza, em suma, é (re)feita para trabalhar mais, mais rápido e melhor" (idem, p. 564).

Uma ilustração útil da diferença entre subsunção formal e subsunção real da natureza pode ser encontrada novamente na indústria florestal. Enquanto o capitalismo inicial se caracterizou pelo extenso corte de florestas antigas e pelo desmatamento que se seguiu, como mostra o exemplo da Finlândia, hoje empresas e agências estatais pretendem intervir na base biológica do crescimento florestal. "Em vez de confrontar as árvores como objetos prontos, a lógica da silvicultura das plantações envolve intervenção contínua e alteração dos processos de crescimento das árvores" (idem, 566). A indústria florestal envolve não apenas a derrubada de árvores e extrair a madeira, mas o uso de fertilizantes e pesticidas químicos, operações intensivas de viveiro para cultivo de mudas, plantio manual e mecânico de árvores, bem como tentativas de manipular diretamente o material genético (cf. idem, p. 566).

Embora a subsunção real da natureza pelo capital não seja novidade, o rápido desenvolvimento da biotecnologia forneceu meios incomparáveis para a sua expansão e intensificação. No biocapitalismo de hoje, a biotecnologia é considerada a chave para solucionar os desafios que obstruem a acumulação capitalista, como as mudanças climáticas, o fim do fornecimento de energia barata e o envelhecimento da população. Enquanto no caso da subsunção formal, a lucratividade poderia ser melhorada simplesmente estabelecendo direitos de propriedade sobre os recursos naturais, a subsunção real da natureza requer a privatização e a comoditização do conhecimento biotecnológico, e não da própria natureza (cf. idem, 564). Hoje, são necessários conhecimentos biocientíficos complexos e experiência tecnológica para intensificar a produtividade dos recursos naturais. ${ }^{12}$

Se voltarmos novamente a investigar os desenvolvimentos paralelos na capitalização do trabalho reprodutivo das mulheres, o que significa a subsunção real da natureza? Quero sugerir que o aparecimento de tecnologias de reprodução assistida (TRA's) transformou as oportunidades para a exploração do trabalho reprodutivo das mulheres em razão da capacidade dessas tecnologias de alterar radicalmente o processo biológico da reprodução humana. $\mathrm{O}$ trabalho biologicamente reprodutivo das mulheres, é claro, nunca ocorreu completamente fora dos circuitos capitalistas de valorização. A prática de reprodução de escravos,

12 Kean Birch e David Tylefield argumentam que os direitos de propriedade mais importantes no setor bioeconômico atualmente são aqueles pertencentes à propriedade de ativos de conhecimento. A realização do valor dos direitos de propriedade imaterial por meio de trocas no mercado é a questão-chave na lucratividade desse setor (cf. BIRCH; TYLEFIELD, 2012, p. 316). 


\begin{tabular}{c|c|c} 
Feminismo, & Dra. Johanna & tradução: Dra. Juliana \\
Capitalismo e Ecologia & Oksala [LUC -EUA] & Lira Sampaio [CP II - R]]
\end{tabular}

por exemplo, foi empregada explicitamente como um meio de expandir a riqueza e a força de trabalho dos proprietários de escravos (cf. DAVIS, 1972). No entanto, hoje com as TRA's, os processos biofísicos de reprodução humana podem ser alterados de maneira a possibilitar a criação de um novo tipo de mercado global de fertilidade. É difícil fornecer contas precisas de seu tamanho, mas mesmo com estimativas cuidadosas é significativo. Algumas estimativas colocam o tamanho do mercado global de barriga de aluguel transnacional sozinho em seis bilhões de dólares anualmente em todo o mundo (cf. SMERDON, 2008, apud MOHAPATRA, 2014, p. 147).

As TRA's alteraram radicalmente o processo de reprodução humana, separando completamente a reprodução do sexo e a maternidade genética da gravidez. Os atos heterossexuais de penetração não são mais necessários para a reprodução biológica porque a fertilização in vitro (FIV) e a inseminação intrauterina (IIU) podem levar à concepção. A comercialização dessas tecnologias implica que, se os pais não puderem conceber sozinhos, poderão comprar esperma e óvulos através de intermediários que controlam o acesso do mercado a esses gametas. Os óvulos da mãe ou doadora são fertilizados com o esperma do pai ou esperma do doador. Se a mãe genética é incapaz de conduzir a gestação até o fim, é possível implantar o embrião no útero da mãe de aluguel que, então, gestará o feto. Esse processo é novamente mediado biotecnologicamente e cada vez mais organizado por meio de intermediários de mercado. As clínicas comerciais examinarão e contratarão as mães de aluguel e prepararão seus revestimentos uterinos para a transferência de embriões. Essa preparação envolve procedimentos médicos demorados e regimes complexos de medicamentos. ${ }^{13}$

Os corpos e as capacidades reprodutivas das mulheres agindo como barrigas de aluguel são, portanto, capitalisticamente apropriadas, mas não como recursos naturais externos. Em vez disso, a barriga de aluguel pode ser vista de modo análogo à subsunção real da natureza pelo capital: o capital é capaz de se apossar e transformar a reprodução biológica e usá-la como fonte para a criação de novos mercados e de novas formas de acumulação de capital. Os corpos das substitutas gestacionais são efetivamente produzidos como natureza explorável e transformados em componentes integrais em um sofisticado processo biotecnológico, bem como nos circuitos capitalistas de valorização. Diferentemente do trabalho reprodutivo da maioria das mulheres, o trabalho reprodutivo das substitutas gestacionais é completamente capitalizado.

13 Para relatos feministas sobre barriga de aluguel comercial transnacional, cf. PANDE, 2009, BAILEY, 2011 e VORA, 2013. 


\begin{tabular}{c|c|c}
\begin{tabular}{c|c} 
Feminismo, \\
Capitalismo e Ecologia
\end{tabular} & $\begin{array}{c}\text { Dra. Johanna } \\
\text { Oksala [LUC - EUA] }\end{array}$ & $\begin{array}{c}\text { tradução: Dra. Juliana } \\
\text { Lira Sampaio [CP II - R]] }\end{array}$
\end{tabular}

\section{Ecopolítica feminista contra o capitalismo}

Afirmo que o feminismo pode desenvolver sua perspectiva crítica hoje apenas no contexto do capitalismo global. Os novos contornos da relação entre vida e política estão intimamente ligados à expansão da acumulação capitalista: é impossível entender as causas fundamentais da crise ambiental hoje sem uma análise crítica do capitalismo global, assim como é impossível entender o rápido desenvolvimento de ciências da vida e sua aplicação em biotecnologias fora da estrutura do biocapitalismo. Portanto, a teorização feminista que defendo aqui assume a forma de uma crítica ao capitalismo. É essencial a teoria feminista reconhecer a existência de imperativos que advêm das características sistêmicas do capitalismo - sua lógica econômica inerente ou leis do movimento. No nível macroeconômico, incluem de maneira importante o objetivo primordial da acumulação capitalista ou o imperativo do crescimento econômico e, no nível microeconômico, o imperativo das empresas individuais de competir umas contra as outras e maximizar seus lucros para sobreviver nessa competição. Esses objetivos explicam ainda mais os imperativos de baratear a mão-de-obra e expandir os mercados, a pressão por melhorias constantes na produtividade da mão-de-obra, as inovações no design de produtos e assim por diante.

Embora muitos teóricos do capitalismo concordem que esses imperativos possam ser reformulados e assumir formas radicalmente diferentes, dependendo do contexto histórico, político e social em que estão inseridos, eles são entendidos, ainda assim, como aqueles que colocam restrições distintas à atividade econômica e política nas sociedades em que prevalece o modo de produção capitalista. É por isso que eles têm um poder de explanação significativo. Compreender esses imperativos e seu caráter convincente fornece à teoria feminista uma estrutura explanatória robusta para dar sentido a uma série de questões políticas, como o mercado reprodutivo global, por exemplo. As clínicas de barrigas de aluguel não estão crescendo na Índia por causa do tempo, que lá é ensolarado.

A teoria feminista não pode operar, no entanto, com noções estáticas ou totalizadoras do capitalismo. A análise do capitalismo deve ser suficientemente complexa para poder distinguir diferentes mecanismos, às vezes contraditórios, que são, contudo, compatíveis com a lógica subjacente da acumulação capitalista. Ao fazer as distinções entre o mecanismo de externalização e aquele de internalização, bem como entre a subsunção formal e a subsunção real da natureza, meu objetivo é fornecer uma consideração teoricamente mais sutil sobre os análogos funcionais entre a apropriação do capitalismo do trabalho reprodutivo das mulheres e as produções da natureza. No entanto, meu principal 


\begin{tabular}{c|c|c} 
Feminismo, & Dra. Johanna & tradução: Dra. Juliana \\
Capitalismo e Ecologia & Oksala [LUC -EUA] & Lira Sampaio [CP II - R]]
\end{tabular}

motivo aqui é essencialmente político, não teórico. O reconhecimento da natureza dinâmica e contraditória do capitalismo é politicamente importante, pois implica considerar que, embora alguns desses mecanismos possam parecer, a curto prazo, inegavelmente bons para as mulheres, o meio ambiente e os países em desenvolvimento, isso não invalida a importância fundamental de uma crítica feminista ao capitalismo.

Também deve ser evidente agora por que uma aliança política entre feminismo e ambientalismo não é apenas um exemplo de política de afinidade na qual objetivos políticos separados podem, ocasionalmente, ser compartilhados. Em vez disso, minha principal alegação é que feministas e ambientalistas compartilham um objetivo político comum em sua resistência ao capitalismo. Primeiro, ambos compartilham o projeto urgente de questionar como é politicamente negociada a linha entre os processos de internalização e externalização do mercado, que foi descrito acima. Como o exemplo da barriga de aluguel deixa claro, uma questão política importante hoje é se diferentes processos da vida biológica ou da natureza são trazidos para dentro do domínio dos mercados ou se seu local apropriado é considerado fora desse domínio. Isso tem consequências diretas para questões políticas urgentes relativas à igualdade de acesso e controle político democrático sobre tais processos, mas também é fundamental para a atribuição de seu significado e valor moral. $O$ simples fato de algo pode ser produzido biotecnicamente, por exemplo, não significa que ele deva ser vendido. Negociar os limites da comoditização é essencialmente um projeto político que exige a imposição de limites nos mercados por motivos éticos e filosóficos.

Segundo, a subsunção real da natureza introduz questões políticas espinhosas sobre riscos, direitos e responsabilidades. O problema incorporado na subsunção real da natureza, incluindo a aplicação das novas biotecnologias, é que essas tecnologias contêm riscos sem precedentes, além de resultados médicos e ambientais imprevisíveis. Esses riscos podem incluir a potencial fuga e proliferação de novas formas de vida, como super-ervas daninhas ou cepas mordazes de vírus e bactérias, ou podem se materializar como complicações médicas resultantes da hiperestimulação dos ovários com doses de hormônios ou da cesariana obrigatória dos bebês. Esses riscos sérios que ameaçam a vida devem inevitavelmente levantar questões políticas vexatórias sobre quem deve arcar com esses riscos e fornecer compensação quando as coisas dão errado. Mais uma vez, essa questão implica uma necessidade premente de lutas políticas que unam o feminismo e o ambientalismo contra o biocapitalismo.

Em terceiro lugar, essas duas questões - os limites da mercantilização e os 


\begin{tabular}{c|c|c} 
Feminismo, & Dra. Johanna & tradução: Dra. Juliana \\
Capitalismo e Ecologia & Oksala [LUC -EUA] & Lira Sampaio [CP II - R]]
\end{tabular}

riscos na manipulação biofísica da natureza - devem se abrir para uma questão política ainda mais ampla e profunda. Se minha análise estiver correta, então tanto o feminismo como o ambientalismo devem ter interesse em desafiar todo o sistema econômico que é incapaz de reconhecer o valor das externalidades. Apesar do importante desenvolvimento da economia feminista e ambiental, esses campos de investigação tornam evidentes seus próprios limites: o meio ambiente e o trabalho reprodutivo das mulheres têm um valor intrínseco que não pode ser totalmente monetizado e internalizado nos circuitos de uma economia de mercado capitalista. Isso significa que eles continuam a ser menos valorizados e depredados no sistema capitalista de troca de mercadorias. $\mathrm{O}$ absurdo de tentar monetizar o imensurável torna-se óbvio quando nos fazemos perguntas como qual é o valor econômico do planeta ou o que você estaria preparado para pagar pela vida de seu filho. A ecopolítica feminista deve, portanto, partir do reconhecimento de que precisamos de um sistema econômico no qual outros valores que não o lucro, as preferências dos consumidores e o crescimento econômico tenham chance de vir à tona.

Em suma, no século XXI, as feministas não têm mais a opção de aderir a formas de política ambiental que tentam apenas preservar uma natureza externa em algum lugar fora dos mercados capitalistas. Em vez disso, o objetivo tem de ser mais radical: elas devem desafiar o próprio sistema capitalista e os múltiplos mecanismos por meio dos quais ele tenta absorver a vida em seus circuitos de valor. As demandas socialistas tradicionais pela regulação dos mercados livres e por uma redistribuição mais justa dos recursos terão de ser componentes cruciais da ecopolítica feminista que prevejo aqui; no entanto, parece claro que tal projeto político não pode ser subsumido na tradicional luta socialista de classes. Um movimento inclusivo pela ecopolítica feminista não pode ser construído sobre a ideologia do trabalho, a emancipação econômica, a luta de classes ou o produtivismo. A razão para colocar o capitalismo em questão hoje não é mais voltada apenas às nossas relações sociais e econômicas exploratórias com outros seres humanos, mas à imensurável devastação que estamos causando ao mundo não humano. 
AHO, Hanna. (2016). Lyhyt oppim€a€ar€a metsien rooliin ilmastopolitiikassa. AGARWAL, Bina. 1992. The gender and environment debate: Lessons from India. Feminist Studies, 18 (1), p. 119-59. Disponível em: https:/www.sll.fi/ajankohtaista/blogi/lyhyt-oppimaara-metsien-rooliin-ilmastopolitiikassa. Acesso em 23 out. 2017.

A challenge for ecofeminism: Gender, greening, and community forestry in India. Women \& Environments International, 52/53, p. 12-15, 2001.

BAILEY, Alison. Reconceiving surrogacy: Toward a reproductive justice account of Indian surrogacy. Hypatia, 26 (4), p. 716-41, 2011.

BENSTON, Margaret. The political economy of women's liberation. In: HENNESSY, Rosemary; INGRAHAM, Chrys (ed.) Materialist feminism: Reader in class, difference, and women's lives. New York: Routledge, 1997.

BIRCH, Kean; TYFIELD, David. Theorizing the bioeconomy: Biovalue, biocapital, bioeconomics or. . .what? Science, Technology \& Human Values, 38 (3), p. 299-327, 2012.

BOYD, William; PRUDHAM, W. Scott; SCHURMAN, Rachel A. Industrial dynamics and the problem of nature. Society and Natural Resources, 14 (7), p. 555-70, 2001.

BRAIDOTTI, Rosi, [et al.] Women, the environment and sustainable development: Towards a theoretical synthesis. London: Zed Books, 1994.

CARLASSARE, Elizabeth. Socialist and cultural ecofeminism: Allies in resistance. Ethics and the Environment, 5 (1), p. 89-106, 2000.

COLLINS, Patricia Hill. Black feminist thought: Knowledge, consciousness, and the politics of em- powerment. Boston: Unwin Hyman, 1990.

CRENSHAW, Kimberlé. Demarginalizing the intersection of race and sex: A black feminist critique of antidiscrimination doctrine, feminist theory and antiracist politics. University of Chicago Legal Forum, 1, p. 139-67, 1989.

DALY, Mary. Gyn/Ecology: The metaethics of radical feminism. Boston: Beacon Press, 1978.

DAVIS, Angela Y. Reflections on the black woman's role in the community of slaves. Massachusetts Review, 13 (2), p. 81-100, 1972.

DAWSON, Michael C. Hidden in plain sight: A note on legitimation crises and the racial order. Critical Historical Studies, 3 (1), p. 143-61, 2016.

FARRIS, Sara R. (2015) The intersectional conundrum and the nation-state. Disponível em: https://viewpointmag.com/2015/05/04/the-intersectional-conundrum-and-the-nation-state/. Acesso em 23 out. 2017.

FEDERICI, Silvia. Revolution at point zero: Housework, reproduction, and feminist struggle. New York: Autonomedia, 2012.

FOLBRE, Nancy; NELSON, Julie A. For love or money - or both? Journal of Economic Perspectives, 14 (4), p. 123-40, 2000.

FOSTER, John Bellamy. Ecology against capitalism. New York: Monthly Review Press, 2002.

FRASER, Nancy. Behind Marx's hidden abode. New Left Review 86, p. 1-17, mar.-abr. 2014.

. Expropriation and exploitation in racialized capitalism: A reply to Michael Dawson. Critical Historical Sudies, 3 (1), p. 163-78, 2016.

GAARD, Greta. Ecofeminism revisited: Rejecting essentialism and re-placing species in a material environ- 
ment. Feminist Formations, 23 (2), p. 26-53, 2011.

GAARD, Greta; GRUEN, Lori. Ecofeminism: Toward global justice and planetary health. In: ZIMMERMAN, Michael E.; CALLICOTT, J. Baird; WARREN, Karen J.; KLAVER, Irene; CLARK, John (ed.) Environmental Philosophy: From Animal Rights to Radical Ecology. 4th edition. Upper Saddle River, NJ: Pearson, 2005.

GRIFFIN, Susan. Woman and nature: The roaring inside her. New York: Harper \& Row, 1978.

, David. The new imperialism. Oxford: Oxford University Press, 2003.

HOCHSCHILD, Arlie. Global care chains and emotional surplus value. In: HUTTON, W.; GIDDENS, A. (ed.) On the edge: Living with global capitalism. London: Jonathan Cape, 2000.

Ilmasto.org. (2008) Vanhat mets€at sittenkin hiilinieluja. Disponível em: http://ilmasto.org/kirjoitukset/ vanhat-metsat-sittenkin-hiilinieluja. Acesso em 23 out. 2017.

KIRK, Gwyn. Standing on solid ground: A materialist ecological feminism. In: HENNESSY, Rosemary; INGRAHAM, Chrys (ed.) Materialist feminism: A reader in class, difference, and women's lives. New York: Routledge, 1997.

KLEIN, Naomi. This changes everything: Capitalism vs. the climate. New York: Simon \& Schuster, 2014.

MARX, Karl. Capital: A critique of political economy. Vol. I. London: Penguin, 1976.

MELLOR, Mary. Breaking the boundaries: Towards a feminist green socialism. London: Virago, 1992.

MERCHANT, Carolyn. The death of nature: Women, ecology, and the scientific revolution. New York: Harper \& Row, 1980.

MIES, Maria. Patriarchy and accumulation on a world scale: Women in the international division of labour. London: Zed Books, 1986/1998.

MOHAPATRA, Seema. A race to the bottom? The need for international regulation of the rapidly growing global surrogacy market. In: DASGUPTA, Sayantani; DASGUPTA, Shamita Das (ed.) Globalization and transnational surrogacy in India: Outsourcing life. Lanham, Md.: Lexington Books, 2014.

Moore, Jason. Capitalism in the web of life: Ecology and the accumulation of capital. New York: Verso, 2015.

NANDA, Meera. "History is what hurts": A materialist feminist perspective on the green revolution and its ecofeminist critics. In: HENNESSY, Rosemary; INGRAHAM, Chrys (ed.) Materialist feminism: A reader in class, difference, and women's lives. New York: Routledge, 1997.

OKSALA, Johanna. The neoliberal subject of feminism. Journal of the British Society for Phenomenology, 42 (1), p. 104-20, 2011.

PANDE, Amrita. Not an "angel", not a "whore": Surrogates as "dirty" workers in India. Indian Journal of Gender Studies, 16 (2), p. 141-73, 2009.

SALLEH, Ariel. Ecofeminism as politics: Nature, Marx and the postmodern. London: Zed Books, 1997.

SANDEL, Michael. What money can't buy: The moral limits of markets. New York: Farrar, Straus \& Giroux, 2012.

SHIVA, Vandana. Staying alive: Women, ecology and development. London: Zed Books, 1989.

SMITH, Neil. Nature as accumulation strategy. Socialist Register, 43, p. 16-36, 2007.

United Nations Population Fund (UNFPA) (2009) State of world population 2009. Facing a changing world: Women, population and climate. Disponível em: https://www.unfpa.org/sites/default/files/pub-pdf/ 
state_of_world_population_2009.pdf. Acesso em 23 out. 2017.

VOGEL, Lise. Marxism and the oppression of women: Toward a unitary theory. Leiden: Brill, 2013.

VORA, Kalindi. Potential, risk, and return in transnational Indian gestational surrogacy. Current Anthropology, 54 (S7), p. S97-S106, 2013.

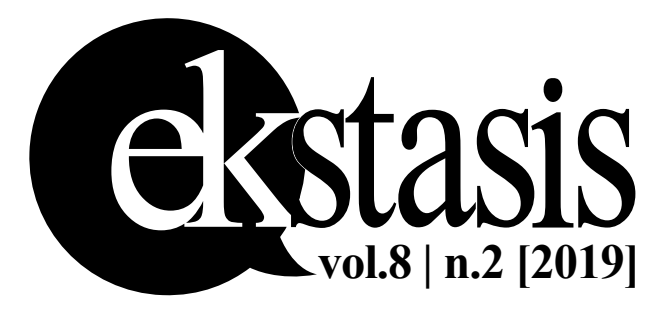

